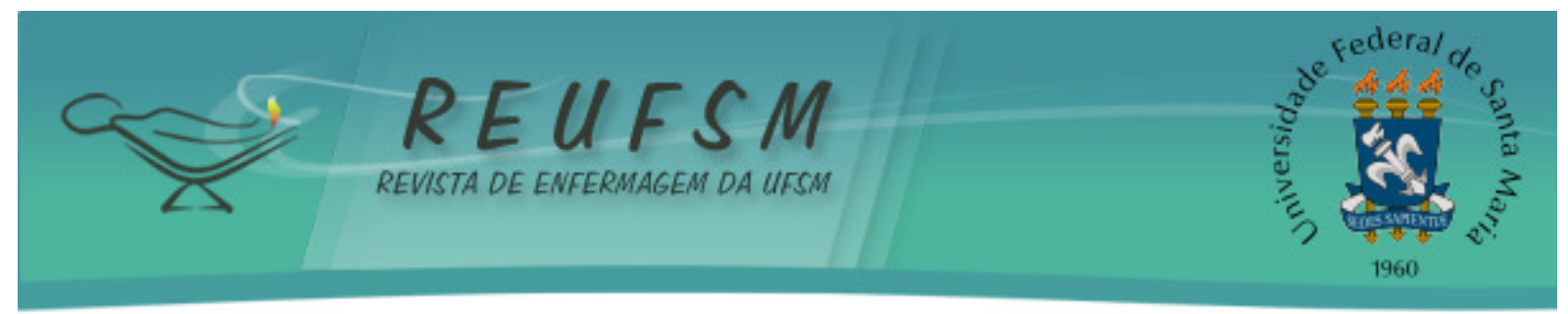

ARTIGO ORIGINAL

\title{
CIDADANIA E O DIREITO À SAÚDE NOS SERVIÇOS RESIDENCIAIS TERAPÊUTICOS
}

\section{CITIZENSHIP AND THE RIGHT TO HEALTH IN THE RESIDENTIAL THERAPEUTIC SERVICES \\ CIUDADANÍA Y EL DERECHO A LA SALUD EN LOS SERVICIOS RESIDENCIALES TERAPÉUTICOS}

\author{
Luciane Prado Kantorski ${ }^{1}$ \\ Adriane Domingues Eslabão ${ }^{2}$ \\ Valéria Cristina Christello Coimbra ${ }^{3}$ \\ Janaina Quinzen Willrich ${ }^{4}$ \\ Cristiane Kenes Nunes ${ }^{5}$ \\ Ariane da Cruz Guedes 6 \\ Valquiria de Lourdes Machado Bielemann ${ }^{7}$
}

RESUMO: Objetivo: avaliar as estratégias utilizadas pelo Serviço Residencial Terapêutico para promover o direito à saúde e à cidadania. Método: trata-se de um estudo qualitativo, de caráter descritivo e analítico, realizou-se no mês de maio de 2010, em um Serviço Residencial Terapêutico do município de Alegrete, no Rio Grande do Sul. Foram realizadas entrevistas semiestruturadas com 12 moradores, as quais foram gravadas e transcritas literalmente. Utilizou-se o círculo hermenêutico-dialético. Resultados: identificou-se, como estratégias utilizadas na produção de saúde e cidadania: a inserção dos moradores do Serviço Residencial Terapêutico em casas próprias, inseridas no município de Alegrete, e a administração do seu próprio dinheiro, quando há autonomia. Conclusão: é através da aquisição de lares fora do residencial inseridos na sociedade e pela independência financeira, em alguns casos, que o direito à cidadania e à saúde é possibilitado.

Descritores: Saúde mental; Desinstitucionalização; Serviços de saúde mental; Participação cidadã; Moradias Assistidas.

ABSTRACT: Aim: to assess the strategies used by the Therapeutic Residentail Service to promote the right to health and citizenship. Method: it consists of a qualitative study, of descriptive and analytical character. The study was carried out in May 2010 at a Therapeutic Residential Service in the town of Alegrete, Rio Grande do Sul. Semi-structured interviews were carried out with 12 residents, which were recorded and literally transcribed. A hermeneutical-dialectical circle was used. Results: sterategies were noticed to reach health production and citizenship: the inclusion of Therapeutic Residential Service II residents in their own houses inserted in the town of Alegrete and the administration of their own Money in cases in which autonomy is found. Conclusion: it is through acquiring

\footnotetext{
${ }^{1}$ Professora Doutora da Faculdade de Enfermagem da Universidade Federal de Pelotas (UFPel). Pelotas, RS, Brasil. E-mail: kantorski@uol.com.br

${ }^{2}$ Enfermeira Pós Graduanda em Abordagem Multidisciplinar em Dependência Química pela Universidade Federal de Rio Grande. Pelotas, RS, Brasil. E-mail: adrianeeslabao@hotmail.com

${ }^{3}$ Professora Doutora da Faculdade de Enfermagem da UFPel. Pelotas, RS, Brasil. E-mail: valeriacoimbra@hotmail.com

${ }^{4}$ Professora Doutoranda da Faculdade de Enfermagem da UFPel. Pelotas, RS, Brasil. E-mail: janainaqwill@yahoo.com.br

${ }^{5}$ Enfermeira Mestranda da Faculdade de Enfermagem da UFPel. Pelotas, RS, Brasil. E-mail: cris_kenes@hotmail.com

${ }^{6}$ Enfermeira Doutoranda da Escola de Enfermagem da Universidade Federal do Rio Grande do Sul. Pelotas, RS, Brasil. E-mail: arianecguedes@gmail.com

${ }^{7}$ Enfermeira Mestre da Universidade Federal de Santa Catarina. Pelotas, RS, Brasil. E-mail: valmb@gmail.com
} 


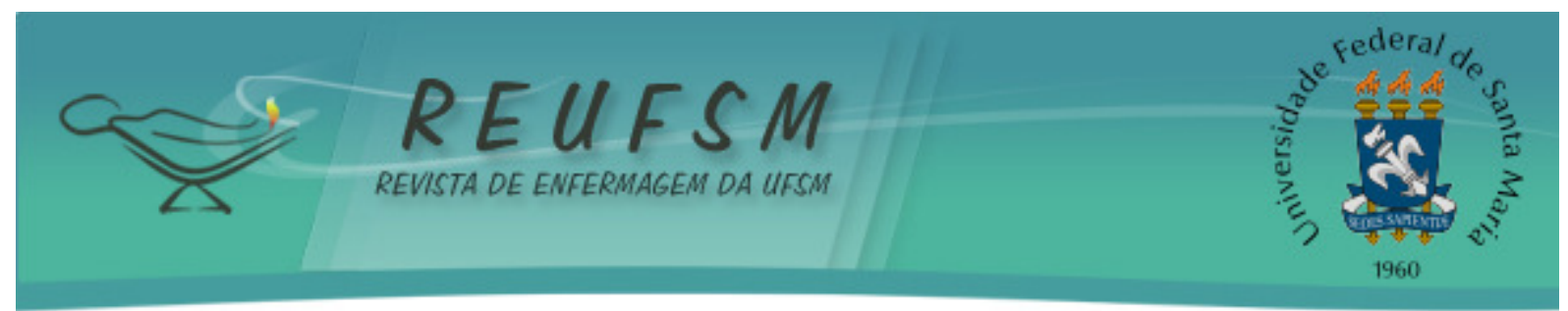

houses out of Residential inserted in the society and through the financial autonomy, in some cases, that the right to citizenship and health is made possible.

Descriptors: Mental health; Deinstitutionalization; Mental health services; Citizen participation; Assisted living facilities.

RESUMEN: Objetivo: evaluar las estrategias utilizadas por el Servicio Residencial Terapéutico para promover el derecho a la salud y la ciudadanía. Método: se trata de un estudio cualitativo, descriptivo y analítico, realizado en mayo de 2010 en un Servicio Residencial Terapéutico en la ciudad de Alegrete, en Rio Grande do Sul. Fueron realizadas entrevistas semiestructuradas con 12 residentes y fueron grabadas y transcritas literalmente. Se utilizo el círculo hermenéutico dialéctico. Resultados: fue identificado como las estrategias utilizadas en la producción de salud y ciudadanía: la inserción de los habitantes de Servicio Residencial Terapéutico en casas propias en la ciudad de Alegrete, y la administración de su propio dinero en caso de que exista autonomía. Conclusión: a través de la compra de viviendas fuera del residencial inseridos en la sociedad y la independencia financiera, en algunos casos, que el derecho a la ciudadanía y a la salud es posibilitado.

Descriptores: Salud mental; Desinstitucionalización; Servicios de salud mental; Participación ciudadana; Instituciones de vida asistida.

\section{INTRODUÇÃO}

A Constituição Federal do Brasil afirma, em seu artigo $1^{\circ}$, incisos II e III, que a cidadania e a dignidade de todo cidadão são fundamentos do Estado Brasileiro. ${ }^{1}$ Compreende-se que é preciso haver políticas capazes de garantir a toda pessoa os direitos de cidadania e, dentre eles, o direito à saúde.

É nesse sentido que a Constituição Federativa de 1988 trouxe um novo conceito de saúde que deixou de ser apenas a ausência de doença, deslocando-se para uma concepção mais abrangente, envolvendo modos de viver da pessoa a partir da família, trabalho, moradia, educação, lazer e cultura. ${ }^{1}$

Assim, busca-se a cidadania enquanto conjunto de direitos que possibilite o cidadão participar ativamente da vida e da tomada de decisões de uma sociedade. ${ }^{2}$ Desse modo, as mudanças ocorridas têm atingido todo o sistema de saúde brasileiro, inclusive a área de saúde mental que, nos últimos anos, tem vivido o movimento de reversão do modelo manicomial para o de atenção psicossocial de base comunitária.

O impulso desse processo foi a Conferência de Caracas para a Reestruturação da Assistência Psiquiátrica na América Latina em 1990. As resoluções dessa Conferência foram descritas na Declaração de Caracas, e discorreram sobre a garantia dos direitos humanos e civis dos sujeitos em sofrimento psíquico, ressaltando a importância da implantação do modelo de atenção à saúde mental diversificado, comunitário, integral, contínuo e preventivo. ${ }^{3}$

Nesse sentido, no cenário brasileiro as mudanças na política de atenção à saúde mental foram impulsionadas pelo Movimento de Reforma Psiquiátrica (MRP) que nasceu da crítica ao modelo de atenção hospitalocêntrico, ou seja, centrado no hospital psiquiátrico. Esse movimento produziu importantes transformações em quatro campos: teóricoassistencial, técnico-assistencial, jurídico-político e sociocultural. ${ }^{4}$

Assim, as pessoas em sofrimento psíquico atualmente recebem atendimento e suporte de uma Rede de Atenção Psicossocial, composta por serviços substitutivos, como os Centros de Atenção Psicossocial (CAPS) tipo I, II e III, Infantil (CAPSi) e para a dependência química (CAPS AD); ações de saúde no âmbito da Atenção Básica; Núcleos de Atenção a Saúde da Família; Leitos psiquiátricos em hospitais gerais e Serviços Residenciais Terapêuticos (SRT), entre outros serviços e locais na comunidade efetivando a cidadania de seus usuários. ${ }^{5}$ 


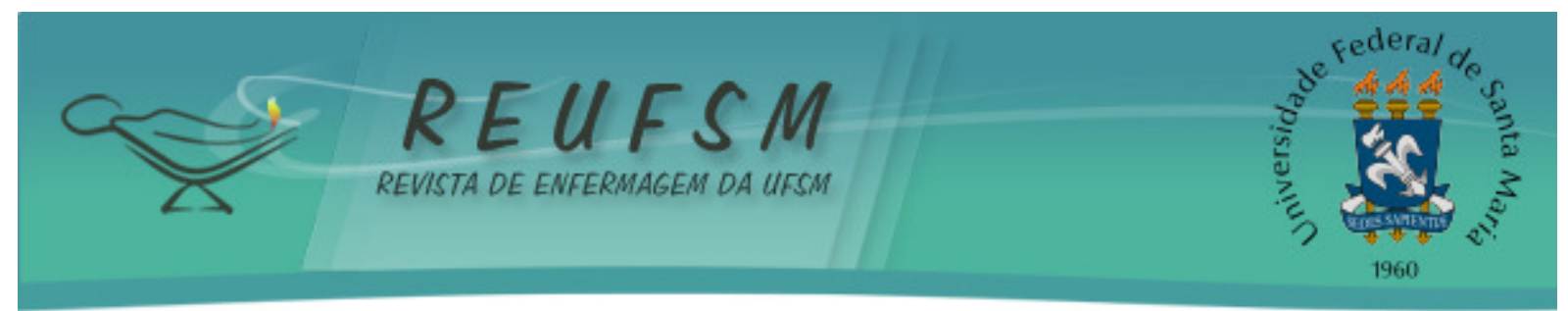

Desse modo, destacam-se os SRT, moradias inseridas na comunidade para pessoas em sofrimento psíquico que foram ou estão internadas, há dois anos ou mais ininterruptos, em hospitais psiquiátricos e que não possuem vínculo familiar e/ou sem apoio deste. ${ }^{6}$

O SRT deve proporcionar um ambiente único de vivência para cada morador, possibilitando experiências individuais enriquecedoras que promovam maior capacidade para enfrentar os desafios da vida. ${ }^{7}$ Dessa forma, tem importante papel na luta pela garantia dos direitos sociais de cidadania dos seus usuários.

A complexidade de garantir o direito à saúde como direito de cidadania às pessoas em sofrimento psíquico envolve um emaranhado de direitos que nos instigam a conhecer e pesquisar as práticas de trabalho dentro dos serviços substitutivos em saúde mental, entendendo-se que não há reforma psiquiátrica sem a garantia efetiva da cidadania na vida das pessoas.

Nessa perspectiva, a questão de pesquisa é: quais as estratégias utilizadas pelo Serviço Residencial Terapêutico para promover o direito à saúde e à cidadania de seus moradores? Tem-se como objetivo avaliar as estratégias utilizadas pelo Serviço Residencial Terapêutico para promover o direito à saúde e à cidadania.

\section{MÉTODO}

Este estudo é um recorte do Projeto de Pesquisa "Redes que reabilitam: avaliando experiências inovadoras de composição de redes de atenção psicossocial” (REDESUL). Aprovado e financiado pelo CNPq e Ministério da Saúde através do Edital MCT-CNPq/CT-Saúde/MS-SCTIEDECIT/33/2008, desdobrou-se em uma pesquisa quanti-qualitativa desenvolvida nas cidades de Alegrete, Bagé, Caxias do Sul, Porto Alegre e Viamão, no Rio Grande do Sul. Para a escolha dessas cidades, utilizou-se, como critério, a existência do SRT na rede de saúde.

Trata-se de um estudo qualitativo, de caráter descritivo e analítico, no qual utilizou-se o círculo hermenêutico-dialético. Foi realizado com 12 moradores do SRT do município de Alegrete no estado do Rio Grande do Sul (RS).

Assim, foram realizadas entrevistas semiestruturadas as quais foram gravadas e transcritas literalmente. Os critérios de seleção dos moradores a serem entrevistados foram residirem no SRT e concordarem em participar da entrevista.

A pesquisa teve início com a seleção de um respondente inicial (R1), sendo realizada uma entrevista aberta para determinar uma construção em relação ao foco da investigação/avaliação. Solicitou-se que o respondente descrevesse como é viver no SRT, incluindo aspectos do dia-a-dia, relacionamento com as pessoas e seu sentimento em residir nesse local. Os temas centrais, conceitos, ideias, valores, problemas e questões propostas por R1 foram analisados pelo pesquisador, em uma formulação inicial da sua construção, designada C1. Desse modo, a análise dos dados ocorreu concomitante à coleta. Após, um segundo respondente (R2) foi entrevistado. Quando R2 colocou todas as questões próprias, os temas oriundos da análise da entrevista de R1 foram introduzidos, e R2 foi convidado a comentá-los. Como resultado, a entrevista com R2 produziu informações não apenas sobre R2, mas também críticas às demandas e construções de R1. 0 pesquisador completou a segunda análise (C2), com construções mais bem informadas e sofisticadas baseadas em duas fontes. $O$ processo foi repetido através da adição de novos informantes, sendo entrevistados todos os componentes de determinado grupo de interesse dos moradores. ${ }^{8}$

A análise do corpus foi realizada da seguinte forma: a partir dos dados das entrevistas foram identificadas unidades de informação relacionadas aos direitos dos moradores do SRT, o que permitiu a constituição da unidade temática "Cidadania", a qual é o foco do presente artigo.

Foram respeitados os princípios éticos conforme a Resolução 196/96, sendo o projeto aprovado pelo Comitê de Ética da Faculdade de Odontologia da Universidade Federal de 


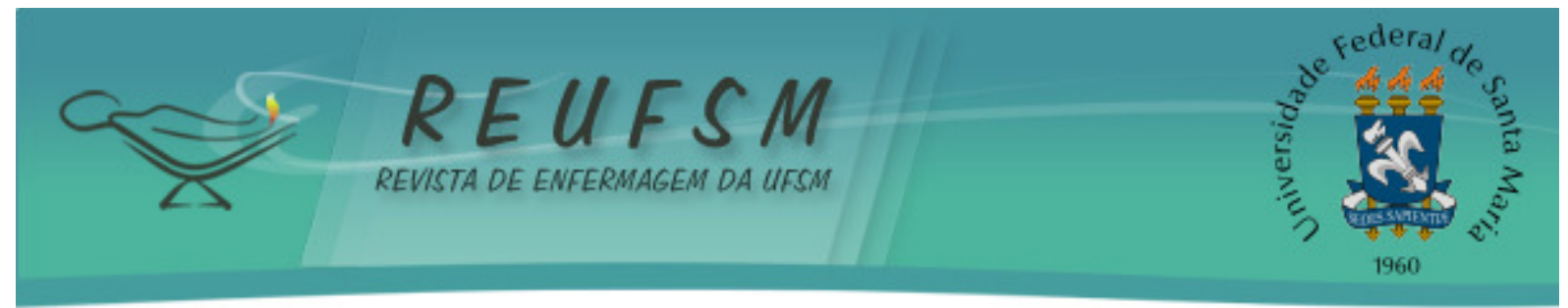

Pelotas, sob parecer $n^{\circ} 073 / 2009$. Os moradores foram identificados com a letra $M$ e com o número de um a 12 , de acordo com a ordem de entrevistados, garantindo seu anonimato.

A escolha do município se deu porque Alegrete é um dos pioneiros do estado do RS na estruturação de um modelo de atenção psicossocial para o cuidado em saúde mental, e possui, no interior da sua rede, um SRT. Seu primeiro CAPS foi fundado em 1989, e sua rede é composta por: CAPS II, CAPS i, CAPS ad, SRT e leitos psiquiátricos em hospitais gerais. ${ }^{10}$ Destaca-se, também, a inexistência de um hospital psiquiátrico nessa cidade, garantindo a integralidade do cuidado em liberdade e privilegiando o território onde vivem os indivíduos em sofrimento psíquico.

\section{RESULTADOS E DISCUSSÃO}

No momento da realização da pesquisa, havia dez moradores no SRT I e oito no SRT II, casas construídas dentro do pátio do SRT, onde moram os usuários com maior autonomia. Assim, o SRT de Alegrete tem utilizado algumas estratégias para o alcance da cidadania e a saúde de seus moradores. Uma estratégia importante foi a aquisição de uma casa própria para três pessoas da Moradia Assistida fora do SRT, ou seja, na comunidade, possibilitando integrar o indivíduo à sociedade.

A aquisição desses imóveis se deu através do Programa Minha Casa Minha Vida, instituído pela Lei $\mathrm{n}^{\circ} 11.977$, de 07 de julho de 2009. ${ }^{11}$ Através da parceria do SRT e da Secretária de Assistência Social do município, foi realizado um levantamento dos moradores do residencial que tinham autonomia, para serem inseridos na comunidade em suas próprias casas e, assim, se deu a concretização do sonho de três pessoas.

Essa conquista dos trabalhadores, usuários, familiares e demais atores sociais que contribuíram para esse processo, pode ser constatada através das falas dos moradores entrevistados.

Eu ganhei da prefeitura uma casa, foi o meu conselheiro que fez eu me inscrever. Eu não esperava nada, aí um dia eu fui na psicóloga ali da Secretaria de saúde [...] ela disse assim: a senhora sabe de uma coisa, foi aprovada, a senhora ganhou casa [...] Ter uma casa significa: melhorar de situação, plantar uma horta, plantar tempero, ah, eu adoro. (M1)

Estou muito bem, tenho vários motivos, eu consegui uma casinha agora na prefeitura, em dezembro está para sair, vou morar na minha casinha. (M5)

O motorista me levou [...] já estava a parede, a janela. [...] para todo mundo conhecer, achei lindo! A janela, a porta, só que o pátio é pra trás. (M2)

Percebe-se, nas falas, que a garantia de casa individual aos moradores do SRT é uma conquista importante no âmbito da cidadania e na promoção da saúde, pois possibilita a inserção social na comunidade e a construção de um espaço próprio do morador.

Assim, a reabilitação psicossocial precisa contemplar três vértices da vida de qualquer cidadão, tais como: casa, lazer e trabalho. Ter um lugar próprio para morar significa ter um cenário de produção de vida, subjetividade, alegrias e tristezas, um espaço de convivência, de pertencimento, trocas sociais de afetos, amizade e 


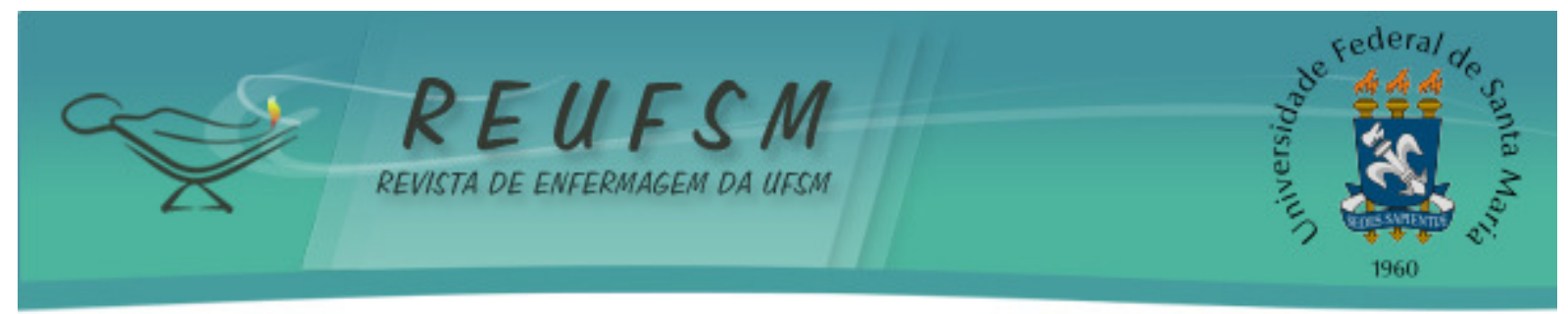

conhecimento. ${ }^{12} \mathrm{~A}$ importância desse espaço está na possibilidade de garantir a cidadania e a saúde como um todo.

Além disso, é possível perceber a felicidade dos moradores com essa conquista, sendo descrita como uma possibilidade de valorização das pequenas coisas que ocorrem no cotidiano da vida, como o cuidado de uma horta, das atividades domésticas, entre outros.

Nesse sentido, a qualidade de vida e saúde de qualquer ser humano está diretamente relacionada à cidadania, que deve ser assegurada por meio de ações coletivas por parte do poder público e da sociedade, contemplando as áreas da saúde, educação, lazer, trabalho, enfim, a garantia de seus direitos de igualdade, não se limitando a questões individuais da pessoa. ${ }^{13}$

Embora a conquista da casa própria seja de suma importância para a vida desses moradores, ainda se percebem algumas dificuldades que eles apresentam para entender o novo processo e lidar com os imprevistos que surgem no cotidiano. Assim como relatado pelos moradores:

Tenho fogão à lenha, mas não posso usar porque a parede não é furada. Isso, isso é da prefeitura como é que a gente vai fazer? (M2)

A única coisa que não tem aqui é meu gato que está lá na antiga morada [...] não deixaram trazer pra casa por causa dos cachorros. (M4)

Nesse sentido, é necessário que os profissionais de saúde atuantes nesse SRT tenham uma abordagem individual com cada morador para garantir a efetividade desse processo para a pessoa. O diálogo é a melhor solução para enfrentar os novos desafios de cada um. Além disso, deve ser viabilizado ao morador manter-se perto de seus animais de estimação e a utilizar os utensílios domésticos que julgar ser necessários em sua nova casa.

Assim, a obtenção da casa própria, juntamente com a possibilidade de ter algum recurso financeiro para gerenciar as necessidades do cotidiano, fazem parte do empoderamento.

O empoderamento não deve ser entendido como transferência de responsabilidades ou apenas o usufruir de benefícios por usuários e familiares, mas como aumento da capacidade de ação e escolha: compreendê-los como coprodutores e participantes de políticas, através da corresponsabilização de diversos atores e do trabalho desenvolvido em rede por inúmeras instâncias sociais. ${ }^{14}$

Nessa perspectiva, o empoderamento é o aumento da autonomia pessoal e coletiva em grupos sociais que possibilita as relações interpessoais e institucionais, sendo necessário trabalhar com sujeitos que passaram por momentos de opressão, dominação e discriminação social como, por exemplo, em hospitais psiquiátricos. Além disso, observamse, nos desafios enfrentados por esses grupos, a necessidade de haver uma rede de apoio, suporte e solidariedade para as pessoas em sofrimento psíquico ${ }^{15}$

Uma questão importante para garantir o empoderamento na vida desses indivíduos é a autonomia econômica que viabiliza a liberdade para a satisfação de algumas necessidades fundamentais. Embora o conceito de autonomia econômica seja mais amplo do que obter o benefício e conseguir administrar o seu dinheiro, para os usuários de saúde mental é um processo complexo.

Alguns moradores do SRT II possuem autonomia para concretizar suas atividades, realizando suas compras, participando de atividades sociais com os amigos através de festas comemorativas e organizando seus gastos financeiros de acordo com as suas necessidades. 


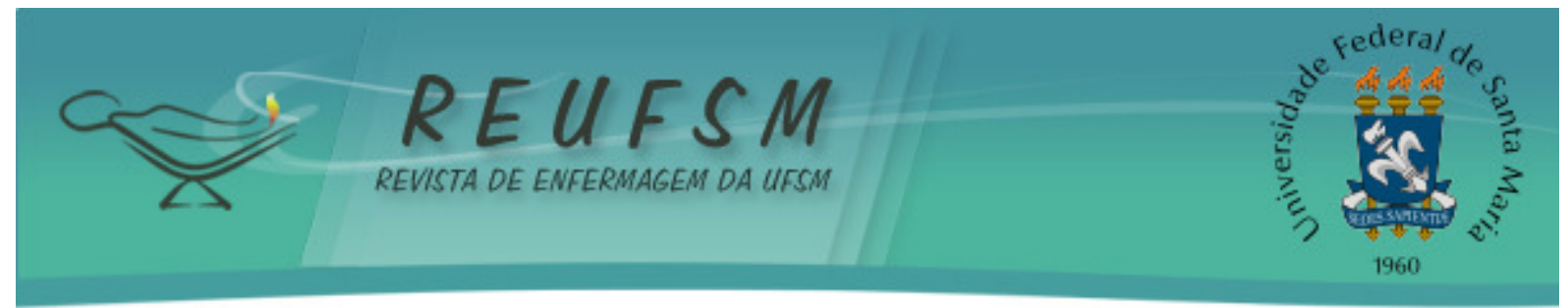

Eu gasto com luz, água, gás, comida pronta e a faxineira [...] que vem uma vez por mês, ou de 20 em 20 dias [...] No Natal, eu colaborei com a festa de Natal com trinta reais [...] na festinha de natal teve um almoço que era várias qualidades de comida, que era umas comidas finas que eu nem sei o nome, depois teve churrasco, teve refrigerante, teve bolo, teve sorvete. (M3)

Faço - compras - é um mercado que eu compro [...] no boliche que tem ali compro. Compro aqui, tenho conta na feirinha, pago por mês [...] ele, confia, a gente paga direitinho. (M6)

Percebe-se, na fala de $M 3$, que participa de festas comemorativas, a opção de contribuir com essas atividades, e isso é um importante poder dos cidadãos.

Nas manifestações que seguem, contraditoriamente, observa-se um importante nível de dependência dos moradores do SRT I com relação aos trabalhadores e às dificuldades em gerir o próprio dinheiro. Os moradores do SRT I são pessoas que têm maior nível de dependência dos trabalhadores e ainda não avançaram na conquista da autonomia.

Falo para ela (técnica de referência) e daí ela me arruma cinco reais para cada um, para comprar uma fruta, uma guaraná [...] Eu busco às vezes frutas e guaraná para tomar de tarde. (M7)

Ela (técnica de referência) é quem pega o meu dinheiro, que compra as coisas pra mim [...] no mês passado ela comprou roupa de baixo. (M9)

Eu peço e eles (trabalhadores do SRT) compram pra mim [...] dão dez reais na sexta, compro guaraná, cigarro, mortadela [...] Eu vou à padaria. (M12)

É possível perceber, através das falas dos moradores $M 3$ e $M 6$, que algumas das atividades realizadas no dia-a-dia tornam-se possíveis por contarem com algum recurso financeiro pessoal e poderem gerenciá-lo. Nesse sentido, ter uma renda possibilita-lhes uma vida com maior liberdade e com dignidade, sendo inseridos na sociedade de forma a usufruir de parte dos bens que esta produz. No entanto, o mesmo não ocorre nas situações dos moradores $M 7, M 8, M 9$ e $M 12$ que ainda apresentam maior nível de dependência.

Dessa forma, a liberdade e a autonomia precisam ser praticadas com os usuários, possibilitando, assim, a sua independência. A autonomia de estar no meio social e ter claro o seu papel é que possibilita ao sujeito ser parte como um todo desta sociedade. A pessoa em sofrimento psíquico deve ter a sua vontade respeitada e aceita pela sociedade, livre de estigmas, garantindo uma inserção plena nesse meio.

Assim, a liberdade é dada pelo caminho que trilhamos e não importa o destino, mas sim a escolha. O sujeito organizará a sua vida e deverá criar condições de coexistência com o outro, pois não há liberdade apenas para o sujeito, mas em todas as relações vivenciadas por ele. ${ }^{16}$

A falta desse recurso financeiro próprio para o morador pode prejudicar o sujeito, visto que é importante dispor de uma renda que lhes possibilite uma maior autonomia e liberdade. Nesse contexto, alguns moradores não possuem renda própria e nenhum tipo de benefício, sendo dependentes de ajuda de outros moradores e do próprio serviço. Assim, 


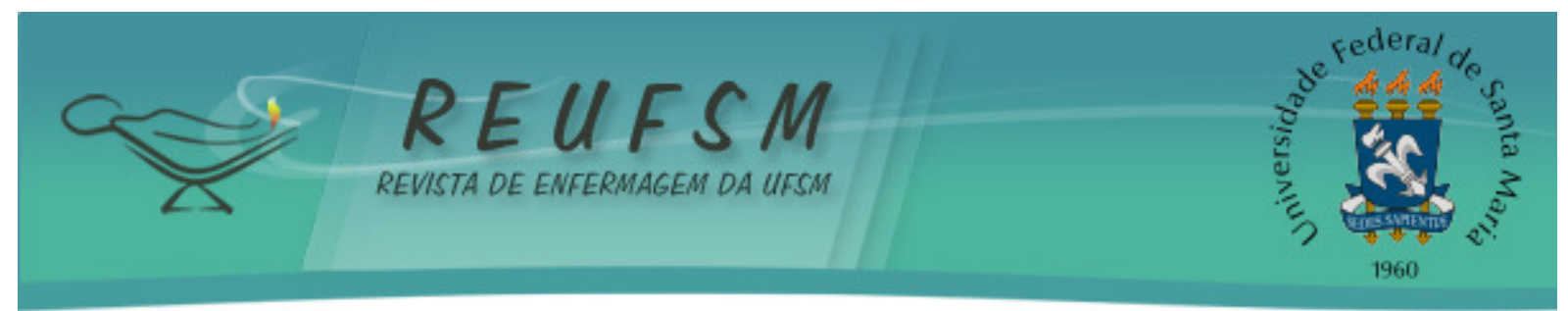

nas falas a seguir percebe-se que os moradores sentem a necessidade de uma renda para suprir as sua necessidades.

Eu pergunto assim: dá para eu tomar banho? Terá o sabonete lá? Eu não tenho xampu, não tenho sabonete, não tenho nada. (M8)

O dinheiro é dos pacientes mesmo, não tem porque não comprar as coisas pra eles. Não tem por que não comprar, se está faltando eu acho que tem que comprar. (M10)

Não é meu como vou pegar se é alheio? Fica mal. [...] eu não tenho ganho não tenho de onde tirar. (M11)

Nessas manifestações, percebe-se a concepção de que o aspecto financeiro é indispensável na vida de qualquer cidadão. Nesse sentido, observa-se a importância em manter os bens necessários de cada pessoa, pagos pelo próprio dinheiro do sujeito e, além disso, a necessidade de haver uma renda para aqueles que não a possuem.

Reflete-se, assim, a relevância em haver uma renda financeira que possibilite a inserção social e facilite a inclusão da pessoa em sofrimento psíquico nos bens da sociedade.

Nessa perspectiva, em um estudo realizado com dez idosos sobre a temática qualidade de vida, um dos principais tópicos apontados foi o relacionado com a posse de recursos financeiros, ou seja, ter um "bom salário". Além desse tópico, os idosos apontaram, ainda, a ausência de doença e o melhor acesso aos serviços de saúde como fatores importantes para qualificar a vida dessas pessoas. ${ }^{17}$

Assim, possuir uma renda financeira obtida através do mercado de trabalho, ou até mesmo de um beneficio do estado, é um dos dispositivos fundamentais para uma vida com cidadania e saúde, possibilitando a inserção das pessoas na sociedade.

O governo federal disponibiliza dois benefícios para pessoas com transtornos mentais, um garantido através da Lei Orgânica da Assistência Social, o auxílio doença, e o "Programa de Volta para Casa", fundamental para moradores de SRT, acometidos por doenças mentais que estiveram internados em hospitais psiquiátricos por um período contínuo de 24 meses ou mais. ${ }^{18}$

O ideal da sociedade é colocar os sujeitos no mercado de trabalho, entretanto, alguns usuários não vão conseguir inserir-se nesse cenário, apesar de ser fundamental a geração de renda. Assim, ressalta-se que quem tem condições de trabalhar ou fazer parte de um projeto de geração de renda deve ser inserido.

Embora a garantia do auxílio financeiro seja necessária, destaca-se a importância do próprio trabalho que garante ao cidadão um espaço na sociedade e a convivência com pessoas diferentes do seu convívio social.

Assim, apostar no ser humano remete a acreditar na potencialidade das pessoas em sofrimento psíquico, na transformação de padrões e condutas e na aquisição de aptidões que lhes permitam viver e interagir em sociedade. ${ }^{19}$

Por fim, observa-se a importância do trabalho de cidadania e inserção social desses moradores por estarem sendo inseridos na sociedade em suas próprias casas, e pela possibilidade de gerirem o seu recurso financeiro e o seu cotidiano. Esse é um importante passo que o SRT de Alegrete vem possibilitando em termos de cidadania, para essas pessoas. 


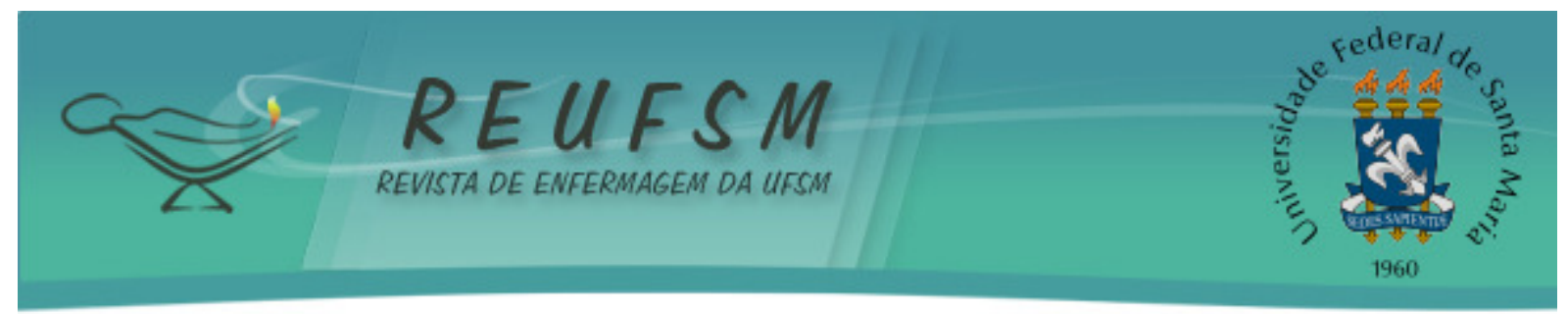

\section{CONSIDERAÇÕES FINAIS}

Diante desse contexto, é possível refletir sobre a importância dos direitos sociais, como a cidadania, na vida desses moradores, possibilitando-lhes uma vida digna e feliz. Assim, é pela aquisição de casas próprias fora do SRT II, inseridos na sociedade e pela condição de terem um recurso financeiro e poder gerenciá-lo, em alguns casos, que o direito à cidadania e à saúde lhes é possibilitado.

Através desses moradores, demonstrou-se que é viável ir além dos Serviços Residenciais Terapêuticos, é possível a inserção social na sociedade em seus próprios espaços, em suas próprias casas.

Além disso, é necessário considerar que o próprio fato de estar morando em um SRT, em vias de transição para suas próprias residências, é uma importante conquista para esses moradores, já que muitas pessoas em sofrimento psíquico ainda se encontram confinadas em instituições fechadas, privadas de seus direitos de cidadania.

\section{REFERÊNCIAS}

1. Brasil. Constituição (1988). Constituição da República Federativa do Brasil: promulgada em 5 de outubro de 1988. Brasília (DF).

2. Dallari DA. Direitos humanos e cidadania. $2^{a}$ ed. São Paulo (SP): Moderna Editora; 2004. $112 \mathrm{p}$.

3. Organização Mundial da Saúde - Organização Pan-Americana de Saúde. Declaração de Caracas. 14 -17 de novembro de 1990.

4. Amarante P. Saúde mental e atenção psicossocial. $20^{\mathrm{a}}$ ed. Rio de Janeiro (RJ): Fiocruz; 2007. $120 \mathrm{p}$.

5. Ministério da Saúde (BR). Relatório Final da IV Conferência Nacional de Saúde Mental Intersetorial. Brasília (DF): Ministério da Saúde/Conselho Nacional de Saúde; 2010. 210 p.

6. Brasil. Ministério da Saúde. Secretaria de Atenção à Saúde. Saúde Mental em Dados 9, ano VI, n 9. Informativo eletrônico. Brasília (DF): Ministério da Saúde; 2011.

7. Santos Junior HPO, Silveira MFA, Oliveira CC. Além dos muros manicomiais: conhecendo a dinâmica das residências terapêuticas. Rev Bras Enferm (Brasília) [Internet]. 2009 [acesso em 2013 jan 10];62(2):87-93. Disponível em: http://www.scielo.br/pdf/reben/v62n2/a03v62n2.pdf.

8. Lincoln YS, Guba EG. Naturalistic inquiry. Newbury Park: Sage Publications; 1985. 415 p.

9. Brasil. Ministério da Saúde. Resolução n 196, de 10 de outubro de 1996. Aprova diretrizes e normas regulamentadoras de pesquisas envolvendo seres humanos. Brasília; 1996.

10. Ministério da Saúde (BR). Conselho Nacional de Desenvolvimento Científico e Tecnológico CNPq. Avaliação dos CAPS da Região Sul do Brasil (CAPSUL): relatório. Coordenação Luciane Prado Kantorski. Pelotas (RS): Universidade Federal de Pelotas; 2007. 437 p.

11. Brasil. Presidência da República. Casa Civil. Subchefia para Assuntos Jurídicos. Lei № 11.977, de 7 de julho de 2009. Dispõe sobre o Programa Minha Casa, Minha Vida. Brasília (DF).

12. Saraceno B. Libertando identidades: da reabilitação psicossocial à cidadania possível. $2^{\mathrm{a}}$ ed. Rio de Janeiro: TeCorá; 2001. 178 p. 


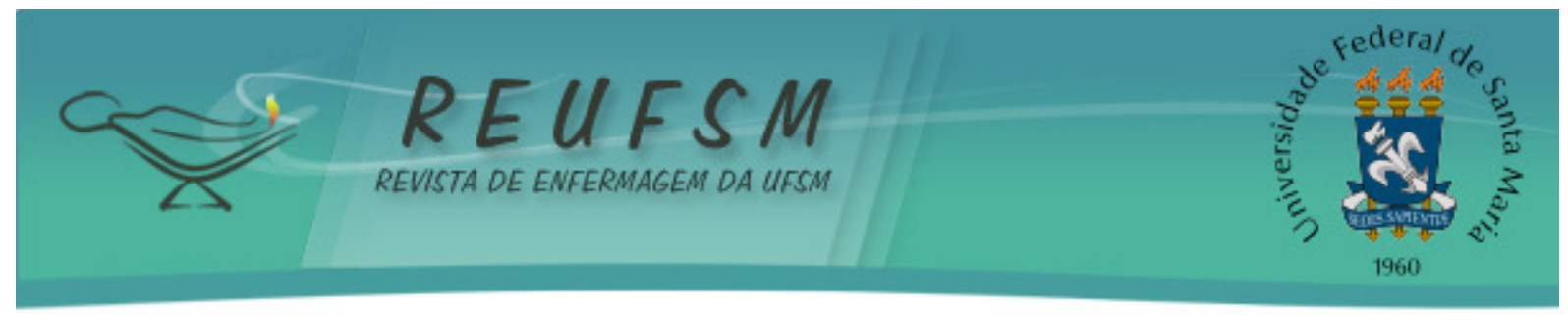

13. Dimenstein $M$, Liberato $M$. Desinstitucionalizar é ultrapassar fronteiras sanitárias: o desafio da intersetorialidade e do trabalho em rede. Cad Bras Saúde Mental [Internet]. 2009 [acesso em 2013 jan 22]; jan-abr;1(1): s/n. (CD-ROM). Disponível em: http://www.esp.rs.gov.br/img2/21_Magda_dimenstein.pdf

14. Almeida KS, Dimenstein M, Severo AK. Empoderamento e atenção psicossocial: notas sobre uma associação de saúde mental. Interface Comun Saúde Educ [Internet]. 2010 [acesso em 2013 fev 22];14(34):577-89. Disponível em: http: //www.scielo.br/pdf/icse/v14n34/aop1410.pdf

15. Vasconcellos EM. O poder que brota da dor e da opressão - empowerrment, sua história, teorias e estratégias. $1^{\text {a }}$ ed. São Paulo (SP): Paulus; 2003.

16. Sousa Filho A. Foucault: o cuidado de si e a liberdade, ou a liberdade é uma agonística. In: Anais do IV Colóquio Internacional Michel Foucault [Internet]; 2007 abr 9-12; Natal(RN). [acesso em 2013 jan 25]. Disponível http://www.cchla.ufrn.br/alipiosousa/index_arquivos/ARTIGOS\%20ACADEMICOS/ARTIGOS_ PDF/FOUCAULT,\%200\%20CUIDADO\%20DE\%20SI\%20E\%20A\%20LIBERDADE.pdf.

17. Alves ERP, Dias MD, Costa AM, Silva ARS, Silva MM, Seabra RV. Qualidade de vida: percepção de idosos de uma unidade de saúde da família. Rev Enferm UFSM [Internet]. 2012 [acesso em 2013 abr 25]; set/dez;2(3):487-95. Disponível em: http://cascavel.ufsm.br/revistas/ojs-2.2.2/index.php/reufsm/article/view/5240/pdf.

18. Ministério da Saúde (BR). Manual do Programa "De Volta Para Casa". Brasília (DF); 2003. (Série A; Normas e Manuais Técnicos).

19. Hirdes A. Autonomia e cidadania na reabilitação psicossocial: uma reflexão. Ciênc Saúde Coletiva [Internet]. 2009 [acesso em 2013 jan 10];14(1):165-71. Disponível em: http://www.scielo.br/pdf/csc/v14n1/a22v14n1.pdf.

Data de recebimento: $23 / 04 / 2013$

Data de aceite: $27 / 06 / 2013$

Contato com autor responsável: Luciane Prado Kantorski

E-mail: kantorski@uol.com.br

Endereço: Rua Victor Valpírio 289, Bairro Três Vendas, Pelotas, RS, Brasil. CEP: 96020-250 